\title{
Investigation of the electrophilic reactivity of the biologically active marine sesquiterpenoid onchidal and model compounds
}

\author{
Melissa M. Cadelis ${ }^{*}$ and Brent R. Copp
}

\author{
Full Research Paper \\ Address: \\ School of Chemical Sciences, University of Auckland, Private Bag \\ 92019, Auckland 1142, New Zealand \\ Email: \\ Melissa M. Cadelis* - m.cadelis@auckland.ac.nz \\ * Corresponding author \\ Keywords: \\ dialdehyde; lysozyme; mollusc; onchidal; pyrrole
}

\author{
Beilstein J. Org. Chem. 2018, 14, 2229-2235. \\ doi:10.3762/bjoc.14.197 \\ Received: 02 May 2018 \\ Accepted: 02 August 2018 \\ Published: 24 August 2018 \\ Associate Editor: S. Bräse \\ (C) 2018 Cadelis and Copp; licensee Beilstein-Institut. \\ License and terms: see end of document.
}

\begin{abstract}
The structure of the sesquiterpene onchidal (6), a component of the defensive secretion of the shell-less mollusc Onchidella binneyi, contains a masked $\alpha, \beta$-unsaturated 1,4-dialdehyde moiety, the presence of which has been proposed to be the cause of the feeding deterrent activity exhibited by the mollusc. We have found onchidal acts as an electrophile, reacting rapidly with the model nucleophile $n$-pentylamine forming diastereomeric aminated pyrrole adducts. Somewhat surprisingly, no reaction was observed between onchidal and $n$-pentanethiol. Structurally simplified $n$-pentyl 11-13 and cyclohexylmethyl 15-17 analogues of onchidal were prepared and demonstrated similar amine-selective reactivity. Onchidal and analogues reacted with the model protein lysozyme, forming covalent adducts and leading to protein cross-linking. These results provide preliminary evidence supporting the molecular mechanism of biological activity exhibited by onchidal.
\end{abstract}

\section{Introduction}

More than 80 terpenoid natural products containing the 1,4dialdehyde moiety have been isolated from sources such as fungi, algae, sponges and molluscs [1]. Many of these natural products exhibit biological activity, ranging from anti-inflammatory to antimicrobial and antifeedant activities [1]. The prototypical examples polygodial (1) and scalaradial (2, Figure 1) both exhibit antifeedant activity against worms and fish [1,2], with recent studies also showing that $\mathbf{1}$ is a potential lead as a marine antifouling agent [3].
The ichthyotoxic masked dialdehyde caulerpenyne (3), a major component of extracts of the green alga Caulerpa taxifolia, exhibits antiproliferative activities as well as wound healing abilities with the latter resulting from rapid transformation to the highly reactive 1,4-dialdehyde, oxytoxin 2 (4) [4-6]. Oxytoxin 2 (4) is itself a natural product, produced by the mollusc Oxynoe olivacea from a diet-derived (Caulerpa algae) precursor and is predominantly present in the predator-deterring mucous secretion of the mollusc [7]. Two structurally-related masked dialde- 
<smiles>CC1(C)CCC[C@]2(C)C(C=O)C(C=O)=CCC12</smiles>

polygodial (1)<smiles>CC(C)=CC#CC(C)=CCC=C(C=O)CC=O</smiles>

oxytoxin 2 (4)

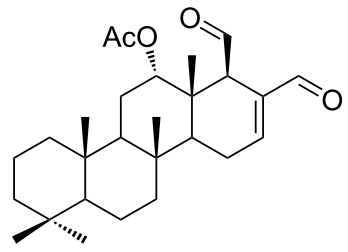

scalaradial (2)<smiles>CC(=O)OC=CC(C=O)=CCC1C(C)=CCCC1(C)C</smiles>

5<smiles>CC(=O)O/C=C(/C=C/OC(C)=O)C(C/C=C(\C)C#CC=C(C)C)O[C+](C)=O</smiles>

caulerpenyne (3)<smiles>C=C1CCCC(C)(C)C1CC=C(C=O)C=COC(C)=O</smiles>

onchidal (6)

Figure 1: Masked and unmasked 1,4-dialdehyde natural products 1-6.

hydes, 5 (from Caulerpa ashmeadii) [8] and onchidal (6) [9,10] (from the defensive secretion of the mollusc Onchidella binneyi) also exhibit biological properties including feeding deterrence, antibacterial and anticholinesterase activities.

Chemical reactivity studies using polygodial (1), scalaradial (2) and caulerpenyne (3) have demonstrated evidence of pyrrole formation upon reaction with primary amines, with conclusions drawn attributing bioactivities such as antifeedant activity to this chemical reactivity $[1,11-13]$. In an effort to ascertain whether the mollusc metabolite onchidal is susceptible to nucleophilic attack in a similar manner, herein we report on the reactivity of onchidal and a library of simplified $n$-pentyl and cyclohexylmethyl model compounds towards thiol and amine nucleophiles as well as their reactivity towards a model protein target, lysozyme.

\section{Results and Discussion}

Preliminary studies of the reactivity of onchidal (6) towards 1-pentanethiol or 1-pentylamine were undertaken in $\mathrm{CDCl}_{3}$ solvent in an NMR tube. Somewhat to our surprise, no reaction was observed with 1-pentanethiol, even with incubation in the presence of excess thiol for one week [14]. In contrast, incubation with excess 1-pentylamine rapidly afforded a mixture of products, as identified by changes in the ${ }^{1} \mathrm{H}$ NMR spectrum. Signals attributable to $N$-alkyl-3-substituted pyrroles 7-9 and $N$-pentylacetamide $10\left[\delta_{\mathrm{H}} 7.62 \mathrm{t}, J=4.7 \mathrm{~Hz} ; 2.28 \mathrm{~m}\right]$ were observed. Purification by silica gel column chromatography, eluting with $\mathrm{CH}_{2} \mathrm{Cl}_{2}$, afforded pyrrole adduct 7 as the free base. Elution with $\mathrm{CH}_{2} \mathrm{Cl}_{2} / \mathrm{MeOH}$ afforded two fractions with the first comprised of a single diastereomer as a salt $\mathbf{8}$, while a second fraction was obtained as a diastereomeric mixture (8:9, $3: 1$ ), again as salts (Scheme 1). Mass spectrometric data observed for 7 supported the formation of a diaminated pyrrole product, with a protonated molecular ion of $\mathrm{m} / \mathrm{z} 373.3556$ $[\mathrm{M}+\mathrm{H}]^{+}$corresponding to a formula of $\mathrm{C}_{25} \mathrm{H}_{45} \mathrm{~N}_{2}$ (requires 373.3577). NMR data further supported such a structure, with pyrrole signals observed at $\left[\delta_{\mathrm{H}} 6.57-6.55, \mathrm{~m}, \mathrm{H}-1\right.$ " and $\mathrm{H}-4$ "; 6.06, br s, H-3"; $\delta_{\mathrm{C}} 120.6$ (C-2" and C-4"); 118.5 (C-1"); 106.8 $(\mathrm{C}-3 ")]$ and pentylamine substitution at $\mathrm{C}-1\left[\delta_{\mathrm{H}} 3.50-3.46, \mathrm{~m}\right.$; $\delta_{\mathrm{C}}$ 54.1]. In the case of the more polar products 8 and $\mathbf{9}$, $(+)$-ESIMS derived the same formula as for 7 , while differences observed in ${ }^{1} \mathrm{H}$ NMR shifts for $\mathrm{H}-1 / \mathrm{H}-2 / \mathrm{H}-1$ ' between 7 and $\mathbf{8}\left[\delta_{\mathbf{8}_{-7}}, \Delta \delta+1.29-0.42\right]$ suggested $\mathbf{8} / \mathbf{9}$ were purified as salts.

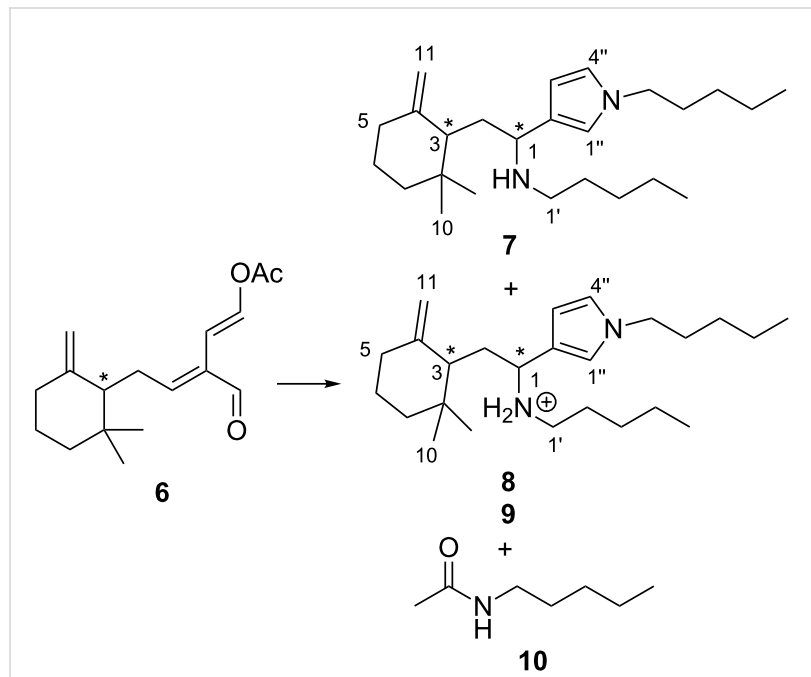

Scheme 1: Products of the reaction of onchidal (6) with 1-pentylamine Reagents and conditions: 1-pentylamine (excess), $\mathrm{CDCl}_{3}$, overnight.

A mechanism that leads to the formation of diaminated pyrrole adduct 7 starts with amine-induced formation of a 1,4-dialdehyde, which then undergoes Paal-Knorr pyrrole formation to 
give an azafulvinium intermediate (Scheme 2). This intermediate could then undergo trapping with an additional mole of amine nucleophile to give 7 as a mixture of diastereomers.

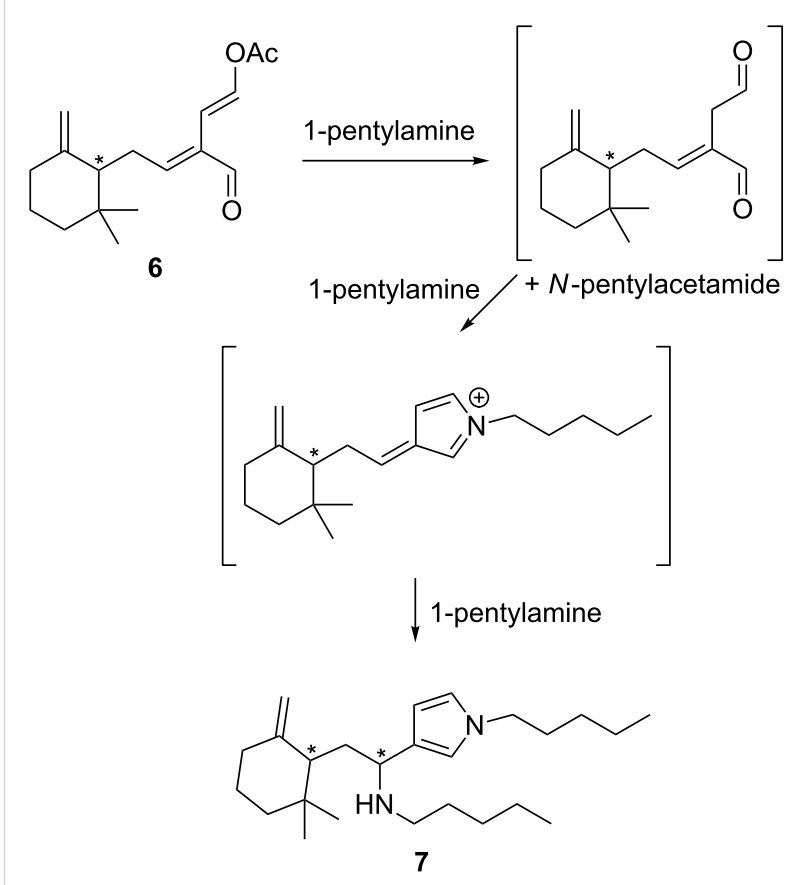

Scheme 2: Proposed mechanism for formation of onchidal diaminated adducts.

In an effort to reduce the complexity of the NMR spectra observed for the diastereomeric onchidal-pyrrole adducts, a range of simpler achiral $n$-pentyl 11-14 and cyclohexylmethyl 15-18 side-chained model compounds, as either the dialdehyde or masked dialdehyde variants, were prepared (Figure 2).

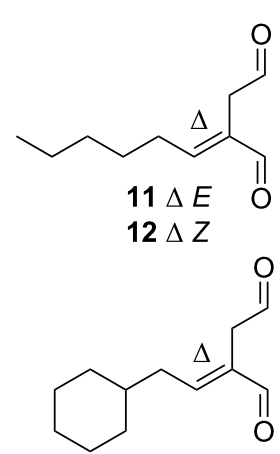

$15 \Delta E$

$16 \Delta Z$
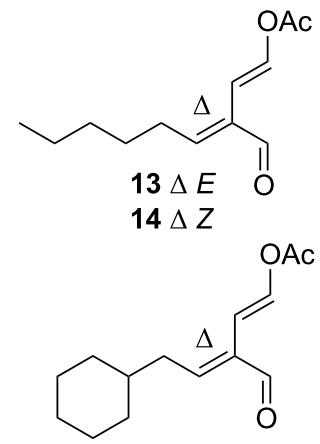

$17 \Delta E$

$18 \Delta Z$
Figure 2: Target onchidal model compounds 11-18.

Horner-Wadsworth-Emmons (H.W.E.) reaction of $n$-hexanal with phosphonoester 19 [15] afforded an $E / Z$ mixture of olefinic diesters, purification of which by silica gel column chromatography afforded a fraction of the desired $E$ diester $\mathbf{2 0}$ (60\%), a second fraction comprised of a 5:1 E/Z mixture and a third fraction of $Z$ diester 21 (10\%, Scheme 3). The reduction of diesters $\mathbf{2 0}(E)$ and $\mathbf{2 1}(Z)$ with $\mathrm{LiAlH}_{4}$ afforded diols $\mathbf{2 2}$ and $\mathbf{2 3}$ in $63 \%$ and $67 \%$ yield, respectively. Subsequent oxidation of 22 with DMP afforded dialdehyde $\mathbf{1 1}$ in 31\% yield. Correspondingly, the reaction of diol 23 with DMP afforded a mixture of dialdehyde 11 with dialdehyde 12 (1:1). Attempts at chromatographic separation of these two isomers resulted in degradation of $\mathbf{1 2}$. Final conversion of $\mathbf{1 1}$ to enol acetate $\mathbf{1 3}$ was achieved by overnight reaction with pyridine and acetic anhydride. Purification by silica gel column chromatography afforded the desired $E, E$ enol acetate $\mathbf{1 3}$ in $17 \%$ yield. A lack of purified dialdehyde $\mathbf{1 2}$ prevented any attempt at the preparation of enolacetate $\mathbf{1 4}$.

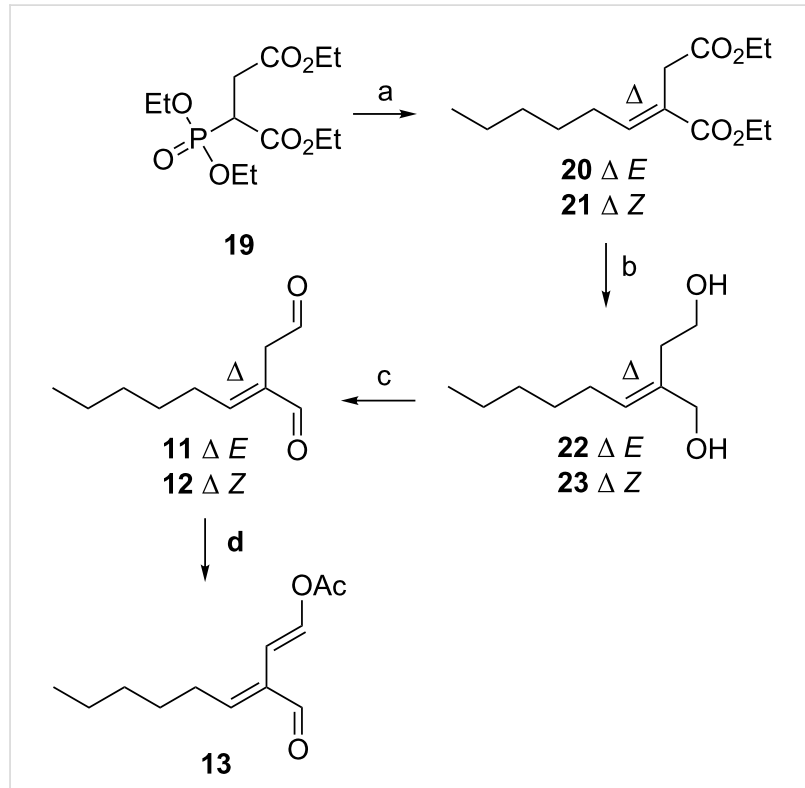

Scheme 3: Synthesis of $n$-pentyl dialdehydes 11 and 12 and enol acetate 13. Reagents and conditions: a) $n$-hexanal ( 0.8 equiv), $\mathrm{LiOH} \cdot \mathrm{H}_{2} \mathrm{O}$ (1.2 equiv), THF, $4 \mathrm{~h}, 60 \%(20), 10 \%(21)$; b) $\mathrm{LiAlH}_{4}$ (2.5 equiv), $\mathrm{Et}_{2} \mathrm{O}, 0^{\circ} \mathrm{C}, 1 \mathrm{~h}, 63 \%(22), 67 \%$ (23); c) DMP (2.5 equiv), $\mathrm{CH}_{2} \mathrm{Cl}_{2}, 4 \mathrm{~h}, 31 \%$ (11); d) $\mathrm{Ac}_{2} \mathrm{O}$ (2 equiv), pyridine (4 equiv), overnight, $17 \%$ (13).

Having developed a successful synthetic route to $n$-pentyl sidechain dialdehyde $\mathbf{1 1}$ and enol acetate 13, the synthesis of analogues 15-18 with a side-chain more comparable to onchidal (6) were attempted. H.W.E reaction of 2-cyclohexylacetaldehyde (24) [16] with phosphonoester 19 afforded a fraction of the desired $E$ diester $\mathbf{2 5}$ in $\mathbf{1 5 \%}$ yield, a fraction of $Z$ diester $\mathbf{2 6}$ in $1.5 \%$ yield and another fraction of a mixture of the two $(5: 1)$ (Scheme 4). The reaction of diesters 25 and 26 with $\mathrm{LiAlH}_{4}$ afforded the corresponding diols 27 and 28 in $61 \%$ and $71 \%$ yield, respectively, which upon oxidation (DMP) afforded dialdehydes $\mathbf{1 5}$ and $\mathbf{1 6}$ in $49 \%$ and 73\% yield, respectively. The 
reaction of dialdehyde $\mathbf{1 5}$ with $\mathrm{Ac}_{2} \mathrm{O}$ and pyridine afforded enol acetate 17 in $43 \%$ yield after purification. Interestingly, the reaction of dialdehyde 16 with $\mathrm{Ac}_{2} \mathrm{O}$ /pyridine only afforded decomposition products, failing to give $\mathbf{1 8}$.

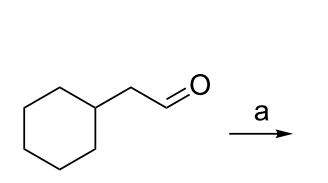

24<smiles>CC(C)=CC(C=O)=CCC1CCCCC1</smiles>
$16 \Delta Z$<smiles>CC(=O)OC=CC(C=O)=CCC1CCCCC1</smiles>

17

Scheme 4: Synthesis of cyclohexylmethyl dialdehydes 15 and 16 and enol acetate 17. Reagents and conditions: a) phosphonate 19 (1.3 equiv), $\mathrm{LiOH} \cdot \mathrm{H}_{2} \mathrm{O}$ (1.5 equiv), THF, $4 \mathrm{~h}, 15 \%(25), 1.5 \%(26)$; b) $\mathrm{LiAlH}_{4}$ (2.5 equiv), $\mathrm{Et}_{2} \mathrm{O}, 0{ }^{\circ} \mathrm{C}, 1 \mathrm{~h}, 61 \%(27), 71 \%(28)$; c) DMP (2.5 equiv), $\mathrm{CH}_{2} \mathrm{Cl}_{2}, 4 \mathrm{~h}, 49 \%$ (15), $73 \%$ (16); d) $\mathrm{Ac}_{2} \mathrm{O}$ (2 equiv), pyridine (4 equiv), overnight, $43 \%$ (17).

The electrophilic reactivity of model dialdehydes 11 and $\mathbf{1 5}$ and enol acetates $\mathbf{1 3}$ and $\mathbf{1 7}$ towards 1-pentanethiol and 1-pentylamine were then studied. As found for onchidal, no reaction (NMR tube) between 11/13/15/17 and 1-pentanethiol was detected, even after one week of incubation. In direct contrast, all four model compounds reacted rapidly with 1-pentylamine, forming pyrrole adducts. The reaction of dialdehyde 11 with 1-pentylamine afforded pyrrole adduct $\mathbf{2 9}$ almost instantaneously as determined by ${ }^{1} \mathrm{H}$ NMR. Purification of the crude reaction product gave $\mathbf{2 9}$ as the free base (15\% yield) and as the salt, 30 (also $15 \%$ yield, Figure 3 ). Spectroscopic and spectrometric analysis of $\mathbf{2 9}$ confirmed the formation of a diamine adduct, with detection of a protonated molecular ion in the $(+)$-ESI mass spectrum at $m / z 307.3097\left(\mathrm{C}_{20} \mathrm{H}_{39} \mathrm{~N}_{2}\right.$ requires 307.3108) and NMR signals appropriate for a 3 -substituted $N$-alkylpyrrole [ $\delta_{\mathrm{H}} 6.57 \mathrm{dd}, J=2.3,2.3 \mathrm{~Hz}, \mathrm{H}-4 " ; 6.54$ br s, H-1"; 6.04 dd, $J=2.3,2.3 \mathrm{~Hz}, \mathrm{H}-3 " ;$; $\delta_{\mathrm{C}} 120.8$ (C-2"), 120.3 (C-4"), 118.4 (C-1"), 106.2 (C-3")].

As proposed for the onchidal-diamine adduct, the formation of $\mathbf{2 9}$ is presumably a consequence of dialdehyde $\mathbf{1 1}$ undergoing

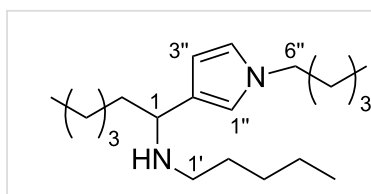

29<smiles>CCCCC[NH2+]C(CC(C)(C)C)c1ccn(CC(C)(C)CC(C)(C)C)c1</smiles>

30
Figure 3: Pyrrole product $\mathbf{2 9}$ and salt $\mathbf{3 0}$ obtained from the reaction of dialdehyde 11 with $n$-pentylamine.

Paal-Knorr pyrrole formation to form an azafulvenium intermediate which is subsequently quenched with another mole of amine nucleophile to form the observed product (Scheme 5).<smiles>CCCCC/C=C(/C=O)CC=O</smiles>

Scheme 5: Reaction of dialdehyde 11 with excess 1-pentylamine to form 29. Reagents and conditions: (a) 1-pentylamine (excess), $\mathrm{CDCl}_{3}$, overnight.

Similar reactivity profiles were observed for each of cyclohexylmethyl dialdehyde 15, and enol acetates 13 and 17, with no reactivity towards 1-pentanethiol being detected, but with rapid reaction with 1-pentyamine to form pyrrole adducts. In the case of dialdehyde 15 , the reaction product was determined to be 31 ( $12 \%$ plus $18 \%$ as the salt, 32, Figure 4$)$, while enol esters 13 and 17 gave 29 and 31 ( $7 \%$ and 5\% yields), respectively, upon reaction with the amine nucleophile.

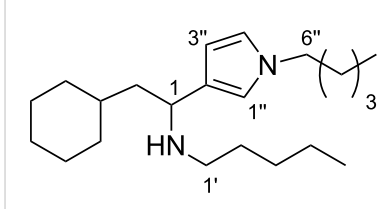

31<smiles>CCCCC(C)NC(CC1CCCCC1)c1ccn([C+]C(C)(C)C)c1</smiles>

32
Figure 4: Pyrrole product 31 and salt 32 obtained from reaction of dialdehyde 15 with $n$-pentylamine.

We next investigated the reactivity of onchidal (6) and analogues 11-13 and 15-17 towards the lysine-rich model protein lysozyme. Previous studies have reported hen egg white 
lysozyme (HEWL) as a suitable target of electrophiles due to its commercial availability, a well-characterized amino acid sequence and the ability for routine (+)-ESIMS analysis to identify covalent adduct formation [17].

Reactivity studies were conducted with commercially available HEWL, in a solution of $\mathrm{MeOH} / \mathrm{H}_{2} \mathrm{O}(+0.5 \%$ formic acid $)$, and the reaction products were investigated by $(+)$-ESIMS. Preliminary reaction of onchidal (6) with lysozyme was conducted in a solvent mixture of $\mathrm{MeOH} / \mathrm{H}_{2} \mathrm{O}(1: 15)$ at $20{ }^{\circ} \mathrm{C}$ and examined regularly by $(+)$-ESIMS. No adducts were detected at 20 hours, but by day $3(72 \mathrm{~h})$, three new peaks representing mass additions of $+198 \mathrm{mu},+216 \mathrm{mu}$, and $+230 \mathrm{mu}$ were detected (Figure 5 and Table 1). These adducts are likely the result of the reaction of lysine residues present in the enzyme [17]. The latter two adducts are proposed to be pyrrole adducts with incorporation of solvolytic $\mathrm{H}_{2} \mathrm{O}$ and methanol, respectively. The $+198 \mathrm{mu}$ adduct could have arisen via elimination of $\mathrm{H}_{2} \mathrm{O}$ or methanol from the corresponding adducts, or alternatively, from deprotonation of the anticipated lysozyme-onchidal azafulvenium intermediate. The adduct product distributions were calculated from the deconvoluted (+)-ESI mass spectrum, identifying a total lysozyme modification yield of $15 \%$ (Table 1). The presence of a large amount of unmodified lysozyme (85\%), even after $72 \mathrm{~h}$, was attributed to the slow reactivity of the enol acetate functionality of onchidal, as observed in the original model studies.

Next, the reactivity of dialdehydes 11, 12, 15 and 16 and enol acetates $\mathbf{1 3}$ and $\mathbf{1 7}$ with lysozyme were examined in a similar manner with mass spectrometry identifying varying degrees of modification. Of the dialdehydes, 11 was the most reactive leading to rapid formation of a white precipitate, speculated to

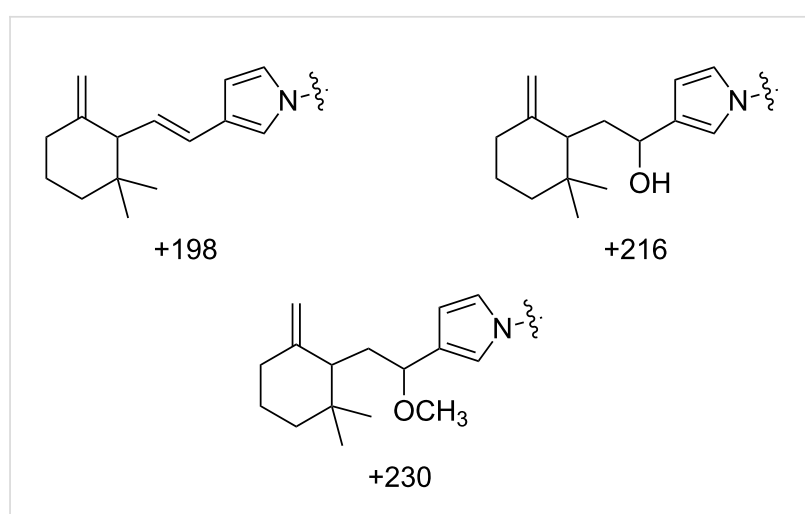

Figure 5: Lysine adducts arising from the reaction of onchidal (6) with lysozyme.

be due to formation of insoluble higher order protein adducts. ESIMS analysis of the supernatant identified only a trace of unreacted lysozyme and detection of ions arising from extensive modification of the enzyme. To simplify the analysis of these adducts, the incubation time for $\mathbf{1 1}$ was shortened to 4 hours, with resultant ESIMS analysis identifying the presence of the three expected pyrrole adducts with mass additions of $+132,+150$ and +164 (Table 1). Interestingly, Z-dialdehyde 12, formed the same adducts as $\mathbf{1 1}$ but at a much slower rate, requiring overnight incubation. In addition to the expected mono-adducts $[+132,+150,+164]$, lysozyme di-adducts were also detected at $+264(2 \times$ alkene $),+282$ (alkene and $\mathrm{OH}),+296$ (alkene and $\mathrm{OMe}),+314(\mathrm{OH}$ and $\mathrm{OMe})$, and $+328(2 \times \mathrm{OMe})$.

Similar reactivity was observed for cyclohexylmethyl $E$-dialdehyde 15 , leading to the formation of a range of mono- $(+158$, $+176,+190)$ and di-adducts $(+316[2 \times$ alkene], +334 [alkene and $\mathrm{OH}],+348$ [alkene and $\mathrm{OMe}],+366[\mathrm{OH}$ and $\mathrm{OMe}],+380$

Table 1: Summary of lysozyme modifications by onchidal (6) and analogues 11-13 and 15-17.a

\begin{tabular}{|c|c|c|c|c|c|c|c|}
\hline \multirow{2}{*}{ No. } & \multirow{2}{*}{ unmod $(\%)^{b}$} & \multicolumn{3}{|c|}{$+1(\%)^{\mathrm{C}}$} & \multicolumn{3}{|c|}{$+2(\%)^{\mathrm{C}}$} \\
\hline & & alkene $^{d}$ & $\mathrm{OH}^{\mathrm{d}}$ & $\mathrm{OCH}_{3}{ }^{\mathrm{d}}$ & alkene $^{d}$ & $\mathrm{OH}^{\mathrm{d}}$ & $\mathrm{OCH}_{3} \mathrm{~d}$ \\
\hline $6^{\mathrm{a}, \mathrm{e}}$ & 85 & 5 & 4 & 6 & 0 & 0 & 0 \\
\hline $11^{f}$ & 37 & 24 & 18 & 21 & 0 & 0 & 0 \\
\hline 12 & 13 & 10 & 8 & 21 & 5 & 0 & 14 \\
\hline 13 & 82 & 0 & 18 & 0 & 0 & 0 & 0 \\
\hline 15 & 10 & 14 & 7 & 15 & 11 & 0 & 11 \\
\hline 16 & 30 & 18 & 30 & 22 & 0 & 0 & 0 \\
\hline $17^{\mathrm{e}}$ & 93 & 2 & 3 & 2 & 0 & 0 & 0 \\
\hline
\end{tabular}

aStandard reaction conditions: $50 \mu \mathrm{M}$ substrate, $10 \mu \mathrm{M}$ lysozyme, in $\mathrm{MeOH} / \mathrm{H}_{2} \mathrm{O}$ at $20^{\circ} \mathrm{C}$ for 20 hours (unless otherwise noted). Product distribution

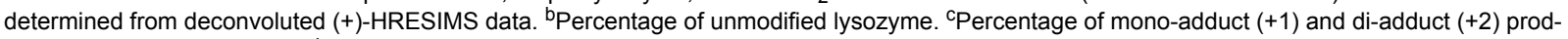
ucts detected by (+)-ESIMS. dAlkene-, hydroxy and methoxy group containing adducts detected. In the case of di-adducts, ions observed consistent

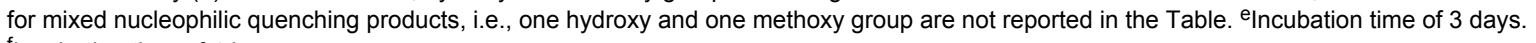
Incubation time of 4 hours. 
[2 $\times$ OMe]) $($ Table 1$)$, while $Z$-dialdehyde 16 was comparatively less reactive, forming only mono-adducts. As expected, enol acetates 13 and 17 were only slowly reactive, giving $18 \%$ and $7 \%$ yield of adducts, respectively, with 17 requiring 72 hour incubation.

Sodium dodecyl sulfate polyacrylamide gel electrophoresis (SDS-PAGE) was used to look for the presence of protein crosslinking arising from the incubation of dialdehydes $\mathbf{1 1}$ and $\mathbf{1 5}$ and enol acetate $\mathbf{1 3}$ with lysozyme. Bands corresponding to dimers $(28 \mathrm{kDa})$ were evident for both the $n$-pentyl and cyclohexylmethyl dialdehydes, with a faint band at $50 \mathrm{kDa}$ also evident in the $n$-pentyl dialdehyde incubation reaction, indicating the presence of lysozyme trimers (Figure 6). No crosslinking was detected for enol acetate $\mathbf{1 3}$, likely due to its low reactivity as determined from the $n$-pentylamine incubation studies.

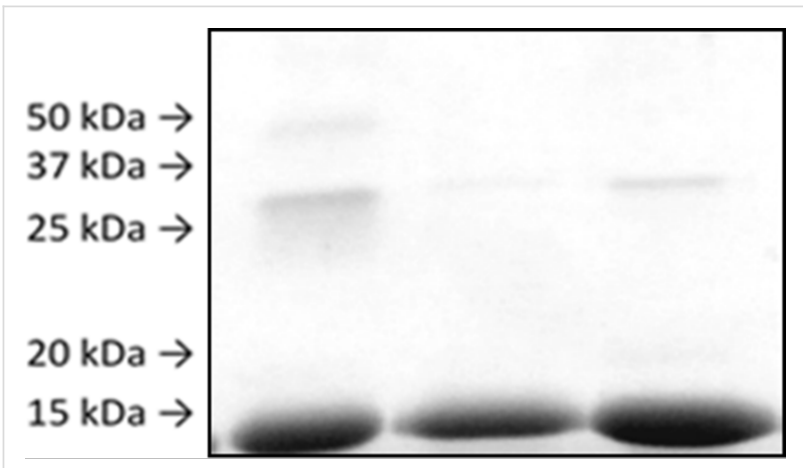

Figure 6: SDS-PAGE separation of lysozyme after modification with 11 (left), 13 (middle), 15 (right).

\section{Conclusion}

A chemical reactivity study of the opisthobranch mollusc metabolite onchidal (6) has identified that it can react with amines to form pyrrole products. The reaction was presumed to proceed via amine-mediated conversion of the enolester containing natural product to a 1,4-dialdehyde, which then undergoes Paal-Knorr pyrrole formation. Structurally simplified $n$-pentyl- and cyclohexylmethyl-dialdehydes were synthesized and found to undergo similar pyrrole forming reactions with pentylamine. These reactions were also apparent with the lysine-rich enzyme hen egg white lysozyme, with onchidal (6) and model compounds 11-13 and 15-17 affording pyrrole adducts of the enzyme that were detected by $(+)$-ESIMS The more reactive dialdehydes were also found to lead to protein crosslinking with formation of lysozyme dimers and trimers. Taken together, these results support the hypothesis that onchidal (6) could be used in chemical defense in a similar manner to related sesquiterpenoid dialdehydes and enol esters.

\section{Supporting Information}

\section{Supporting Information File 1}

Experimental procedures and characterization data of new compounds.

[https://www.beilstein-journals.org/bjoc/content/ supplementary/1860-5397-14-197-S1.pdf]

\section{Supporting Information File 2}

${ }^{1} \mathrm{H}$ and ${ }^{13} \mathrm{C}$ NMR spectra of synthesized compounds. [https://www.beilstein-journals.org/bjoc/content/ supplementary/1860-5397-14-197-S2.pdf]

\section{Acknowledgements}

We thank Dr. Michael Schmitz and Tony Chen for their assistance with acquisition of NMR and mass spectrometric data.

\section{ORCID ${ }^{\circledR}$ iDs}

Melissa M. Cadelis - https://orcid.org/0000-0003-3883-0109 Brent R. Copp - https://orcid.org/0000-0001-5492-5269

\section{References}

1. Dasari, R.; De Carvalho, A.; Medellin, D. C.; Middleton, K. N.; Hague, F.; Volmar, M. N. M.; Frolova, L. V.; Rossato, M. F.; De La Chapa, J. J.; Dybdal-Hargreaves, N. F.; Pillai, A.; Mathieu, V.; Rogelj, S.; Gonzales, C. B.; Calixto, J. B.; Evidente, A.; Gautier, M.; Munirathinam, G.; Glass, R.; Burth, P.; Pelly, S. C.; van Otterlo, W. A. L.; Kiss, R.; Kornienko, A. ChemMedChem 2015, 10 2014-2026. doi:10.1002/cmdc.201500360

2. Cimino, G.; Sodano, G.; Spinella, A. Tetrahedron 1987, 43, 5401-5410. doi:10.1016/S0040-4020(01)87721-8

3. Moodie, L. W. K.; Trepos, R.; Cervin, G.; Larsen, L.; Larsen, D. S.; Pavia, H.; Hellio, C.; Cahill, P.; Svenson, J. J. Nat. Prod. 2017, 80, 515-525. doi:10.1021/acs.jnatprod.6b01056

4. Barbier, P.; Guise, S.; Huitorel, P.; Amade, P.; Pesando, D.; Briand, C.; Peyrot, V. Life Sci. 2001, 70, 415-429. doi:10.1016/S0024-3205(01)01396-0

5. Adolph, S.; Jung, V.; Rattke, J.; Pohnert, G. Angew. Chem., Int. Ed. 2005, 44, 2806-2808. doi:10.1002/anie.200462276

6. Jung, V.; Pohnert, G. Tetrahedron 2001, 57, 7169-7172. doi:10.1016/S0040-4020(01)00692-5

7. Cimino, G.; Crispino, A.; Di Marzo, V.; Gavagnin, M.; Ros, J. D. Experientia 1990, 46, 767-770. doi:10.1007/BF01939963

8. Paul, V. J.; Littler, M. M.; Littler, D. S.; Fenical, W. J. Chem. Ecol. 1987, 13, 1171-1185. doi:10.1007/BF01020547

9. Ireland, C.; Faulkner, D. J. Bioorg. Chem. 1978, 7, 125-131. doi:10.1016/0045-2068(78)90043-3

10. Abramson, S. N.; Radic, Z.; Manker, D.; Faulkner, D. J.; Taylor, P. Mol. Pharmacol. 1989, 36, 349-354.

11. Guerriero, A.; Depentori, D.; D’Ambrosio, M.; Pietra, F. Helv. Chim. Acta 1995, 78, 1755-1762. doi:10.1002/hlca.19950780709 12. Potts, B. C. M.; Faulkner, D. J.; De Carvalho, M. S.; Jacobs, R. S. J. Am. Chem. Soc. 1992, 114, 5093-5100. doi:10.1021/ja00039a021

13. Cimino, G.; Spinella, A.; Sodano, G. Tetrahedron Lett. 1984, 25 , 4151-4152. doi:10.1016/S0040-4039(01)90207-2 
14. Avonto, C.; Taglialatela-Scafati, O.; Pollastro, F.; Minassi, A.;

Di Marzo, V.; De Petrocellis, L.; Appendino, G. Angew. Chem., Int. Ed. 2011, 50, 467-471. doi:10.1002/anie.201005959

15. Li, S.; Wang, X.; Liu, L.; Kang, J.; Wang, L.; Liu, H.; Ruan, C.; Nie, A.; Zheng, Z.; Xie, Y.; Zhao, G.; Xiao, J.; Hu, Y.; Zhong, W.; Cui, H.;

Zhou, X. 5-Membered-S-Heterocyclic Compounds and Their Use in Ppreparing of Medicines for Treating or Preventing the Obesity-Relating Diseases. CN Pat. PCT/CN2004/001118, April 6, 2006.

16. Peterlin, Z.; Li, Y.; Sun, G.; Shah, R.; Firestein, S.; Ryan, K. Chem. Biol. 2008, 15, 1317-1327. doi:10.1016/j.chembiol.2008.10.014

17. Schnermann, M. J.; Beaudry, C. M.; Genung, N. E.; Canham, S. M.; Untiedt, N. L.; Karanikolas, B. D. W.; Sütterlin, C.; Overman, L. E. J. Am. Chem. Soc. 2011, 133, 17494-17503. doi:10.1021/ja207727h

\section{License and Terms}

This is an Open Access article under the terms of the Creative Commons Attribution License

(http://creativecommons.org/licenses/by/4.0). Please note that the reuse, redistribution and reproduction in particular requires that the authors and source are credited.

The license is subject to the Beilstein Journal of Organic Chemistry terms and conditions:

(https://www.beilstein-journals.org/bjoc)

The definitive version of this article is the electronic one which can be found at: doi:10.3762/bjoc. 14.197 